\title{
Pengaruh Pendekatan Saintifik terhadap Motivasi Belajar Siswa Kelas IV SD YPK 4 Pniel Kota Sorong
}

\author{
Rizkyani Arifuddin $^{1}$, Ahmad Yulianto ${ }^{2} \& \operatorname{Alman}^{3}$ \\ Program Studi PGSD, Universitas Pendidikan Muhammadiyah Sorong, Indonesia \\ E-mail: rizkyaniarifuddi922@gmail.com
}

\begin{abstract}
Abstrak
Penelitian ini bertujuan untuk mengetahui pengaruh pendekatan saintifik terhadap motivasi belajar siswa. Penelitian dilakukan pada siswa kelas IV di SD YPK 4 PNIEL Kota Sorong, dengan melibatkan responden sebanyak 30 siswa menggunakan teknik sampling jenuh. Metode yang digunakan adalah pendekatan deskriptif kuantitatif, dengan teknik analisis data yakni menggunakan analisis regresi linear sederhana. Hasil penelitian menunjukkan bahwa terdapat pengaruh antara pendekatan saintifik terhadap motivasi belajar, dilihat dari thitung $>$ ttabel, yakni 3,314 > 2,048, dan berdasarkan nilai sig yakni $0,03<0,05$, maka dapat ditarik kesimpulan bahwa $\mathrm{H} 0$ ditolak dan Ha diterima. Artinya pembelajaran dengan pendekatan saintifik memiliki pengaruh yang signifikan terhadap motivasi belajar. Adapun kualitas pengaruh yang diberikan adalah sebesar 28,2\%, sedangkan $71,2 \%$ disebabkan oleh faktor lain diluar dari motivasi belajar. Berdasarkan data hasil uji hipotesis dapat disimpulkan bahwa terdapat pengaruh pendekatan saintifik terhadap motivasi belajar. Pendekatan saintifik dapat menjadi salah satu pilihan untuk meningkatkan motivasi belajar siswa.
\end{abstract}

Kata Kunci: Pendekatan Saintifik; Deskriptif Kuantitatif; Motivasi Belajar.

\begin{abstract}
This study aims to determine the effect of the scientific approach on student learning motivation. The research was conducted on fourth grade students at SD YPK 4 PNIEL, Sorong City, involving 30 students as respondents using saturated sampling technique. The method used is a quantitative descriptive approach, with data analysis techniques using simple linear regression analysis. The results showed that there was an influence between the scientific approach on learning motivation, seen from tcount $>$ ttable, namely 3,314>2,048, and based on the sig value of $0.03<0.05$, it can be concluded that $\mathrm{HO}$ is rejected and $\mathrm{Ha}$ is accepted. This means that learning with a scientific approach has a significant effect on student learning motivation. The quality of the influence given was $28.2 \%$, while $71.2 \%$ was caused by other factors outside of learning motivation. Based on the data from the hypothesis test, it can be concluded that there is an effect of the scientific approach on learning motivation. The scientific approach can be an option to increase student motivation.
\end{abstract}

Keywords: Scientific Approach; Kuantitatif Deskriptif; Learning Motivation. 


\section{PENDAHULUAN}

Kurikulum 2013 menggunakan sebuah konsep pendekatan saintifik/ilmiah dan berbasis kompetensi yang diarahkan pada pencapaian kompetensi yang dirumuskan dalam SKL (Standar Kompetensi Lulusan). Dalam pendekatan saintifik, pembelajaran yang dilakukan berbasis pada fakta yang dapat dijelaskan dengan logika dan melalui proses saintifik yang struktural. Proses pembelajaran yang semula terfokus pada eksplorasi, elaborasi, dan konfirmasi dilengkapi dengan mengamati, menanya, menalar, mencoba, dan mengkomunikasikan (Kemendikbud, 2013). Pada umumnya, proses pembelajaran konvensional, guru merupakan sumber informasi dan guru selalu aktif menjelaskan, menuntun siswa hingga mengerti, sehingga membutuhkan waktu yang lama dalam proses siswa dari tidak mengerti menjadi paham sehingga kurang efisien. Akan tetapi akan berbeda jika proses pembelajaran menggunakaan pendekatan saintifik, dimana masalah yang diberikan guru selalu berdasarkan dengan fenomena yang selama ini terjadi di kehidupan para siswa, lalu siswa mencoba mencari jawaban dari masalah yang diberikan secara mandiri.

Kurikulum 2013 menekankan pembelajaran dengan pendekatan ilmiah (scientific approach) (Sani. 2014) karena pembelajaran ini sangat sesuai dengan teori pembelajaran konstruksivisme dan melalui scientific approach ini dapat meningkatkan keterampilan-keterampilan proses sains pada siswa antara lain mengamati, menanya, menalar, mencoba (melakukan eksperimen) dan membentuk jejaring (berkomunikasi).

\section{Pendekatan saintifik (scientific} approach) dalam pembelajaran sebagaimana dimaksud meliputi mengamati, menanya, mengumpulkan data, mengasosiasikan dan mengkomunikasikan. Sehingga siswa tidak hanya mengetahui fakta atau prinsip, tetapi harus terampil menerapkan pengetahuannya dalam kehidupan (Lestari. 2018 dan Sadriani. 2018). Kegiatan pembelajaran yang direncanakan dengan baik, dan menggunakan pendekatan yang menarikakan berpengaruh pada belajar peserta didik serta memudahkan guru dalam memberikan pemahaman dan perhatian yang lebih terhadap lingkungan. Pemahaman akan lingkungan sekitar penting karena berpengaruh pada kehidupan peserta didik, baik secara kognitif maupun emosional (Lawson, E.T., et al., 2015).

Berbagai aktifitas yang mengakibatkan terjadinya degradasi di lingkungan pun turut berpengaruh pada kehidupan siswa, jadi sudah seharusnya mereka peka terhadap lingkungan sekitar (Braimah\& Lawson, 2014; Moya et al., 2004; dalam Lawson, E.T., et al., 2015). Hal inilah yang mengharuskan kegiatan pembelajaran sebaiknya menggunakan pendekatan saintifik, agar siswa lebih memahami masalah berdasarkan fenomena yang selama ini terjadi di sekitarnya. Akan tetapi masih banyak guru di sekolah yang menemukan kendala dalam melaksanakan langkahlangkah pendekatan saintifik. Banyak guru yang menganggap bahwa informasi atau materi pelajaran hanya bias diperolah dari buku saja, padahal informasi dapat diperoleh dari berbagai sumber belajar.

Pendekatan saintifik dimaksudkan untuk memberikan pemahaman kepada peserta didik dalam mengenal, memahami berbagai materi menggunakan pendekatan ilmiah, bahwa informasi bias berasal dari mana saja, kapan saja, tidak bergantung pada informasi searah dari guru. Oleh karena itu, kondisi pembelajaran yang diharapkan tercipta diarahkan untuk mendorong peserta didik mencari tahu berbagai sumber melalui observasi, dan bukan hanya diberitahu (Daryanto, 2014). 
Sekolah yang ada di Kota Sorong, beberapa diantaranya sudah menerapkan pendekatan saintifik. Diantaranya SD YPK 4 PNIEL Kota Sorong. Setelah melakukan observasi awal yang dilaksanakan, peneliti menemukan fakta bahwa guru di sekolah tersebut sudah menggunakan pendekatan saintifik dalam proses pembelajaran. Mereka berpendapat bahwa dengan menggunakan pendekatan saintifik, motivasi belajar siswa terlihat ada peningkatan, dan dengan motivasi belajar yang tinggi maka akan meningkatkan pula hasil belajar siswa. Serta siswa lebih aktif dan interaktif dalam menyampaikan isu pembelajaran yang diberikan, peningkatan tersebut dapat terlihat dari adanya kemauan siswa untuk belajar, di mana siswa tidak tinggal diam ketika diberikan kesempatan untuk menjawab pertanyaan yang diajukan dan bertanya ketika ada materi yang tidak dimengerti. Selain itu, adanya perubahan pada kebiasaan siswa di mana mereka yang sebelumnya belum mampu memecahkan masalah dengan usaha sendiri, malu bertanya dan menjawab pertanyaan yang diberikan oleh peneliti, akhirnya dapat melakukan aktivitas belajar yang lebih baik.

Permasalahan yang ditemukan di sekolah menunjukkan adanya keterkaitan yang sangat erat antara pengaruh pendekatan saintifik terhadap motivasi belajar yang baik. Hal inilah yang menjadi dasar pentingnya penelitian ini dilakukan untuk mengetahui pengaruh pendekatan saintifik terhadap Motivasi Belajar Siswa.

Pendekatan saintifik merupakan pendekatan didalam kegiatan pembelajaran yang mengutamakan kreativitas dan temuantemuan siswa (Kosasih, 2014). Penerapan pendekatan saintifik dalam pembelajaran melibatkan keterampilan dalam mengamati, mengklasifikasi, mengukur, meramalkan, menjelaskan, dan menyimpulkan ( Sumayasa dkk, 2015). Dalam melaksanakan prosesproses tersebut, bantuan guru diperlukan. Akan tetapi bantuan guru tersebut harus semakin berkurang dengan semakin bertambah dewasanya siswa atau semakin tingginya kelas siswa (Daryanto, 2014).

Pendidikan saat ini berfokus pada faktor-faktor yang mempengaruhi proses pembelajaran siswa dan keberhasilan sekolah. Disadari bahwa pembelajaran bukan hanya soal mentransfer ilmu, tetapi terkait pada proses konstruksi ilmu yang dipengaruhi baik oleh faktor lingkungan sosial, kultural, dan emosional. Dalam mewujudkan hal tersebut, guru diharapkan mampu mengadopsi proses pembelajaran dengan yang dikembangkan dari pemanfaatan lingkungan sekitar sekolah (Neeman, Y.P., \& Barak, M., 2013). Pendekatan yang dapat digunakan agar guru mampu melakukan proses pembelajaran dengan memanfaatkan segala sumber daya yang ada adalah dengan menerapkan pendekatan saintifik.

Motivasi menurut Hamalik (2011), motivasi adalah suatu perubahan energi dalam pribadi seseorang yang ditandai dengan timbulnya afektif dan reaksi untuk mencapai tujuan. Dalam hal ini terdapat tiga unsur yang saling berkaitan yaitu: 1) motivasi dimulai dari adanya perubahan energi dalam pribadi, 2) motivasi ditandai dengan timbulnya perasaan affective arousal yang mula-mula merupakan ketegangan psikologis, kemudian merupakan suasana emosi, 3) Motivasi ditandai dengan reaksireaksi untuk mencapai tujuan.

Motivasi belajar adalah perilaku belajar yang dilakukan oleh si pelajar pada diri si pelajar terdapat kekuatan mental yang berupa keinginan, perhatian, kemauan dan cita-cita. Menurut Sardiman (2010), motivasi belajar merupakan faktor psikis yang bersifat non intelektual. Perananya yang khas adalah 
dalam hal penumbuhan gairah, merasa senang dan semangat untuk belajar. Siswa yang memiliki motivasi yang sangat kuat, akan mempunyai banyak energi untuk melakukan kegiatan belajar.

Hakikat motivasi belajar adalah dorongan internal dan eksternal pada siswa yang sedang belajar untuk mengandalkan perubahan tingkah lakunya. Pada umumnya terdapat beberapa indikator motivasi belajar menurut meliputi: 1) adanya hasrat dan keinginan berhasil; 2) adanya dorongan dan kebutuhan dalam belajar (Asrul et al, 2018); 3) adanya harapan dan cita-cita masa depan; 4) adanya penghargaan dalam belajar; 5) adanya kegiatan yang menarik dalam belajar; 6) adanya lingkungan belajar yang kondusif sehingga memungkinkan siswa dapat belajar dengan baik (Uno, 2011).

\section{METODE PENELITIAN}

Penelitian ini dilaksanakan di SD YPK 4 Pniel Kota Sorong yang terdiri atas 30 responden yang dipilih secara langsung berdasarkan kriteria pengambilan sampel yang sesuai yakni teknik sampling jenuh atau pengambilan sampel keseluruhan dari populasi yang tersedia.

Jenis penelitian yang diterapkan adalah penelitian kuantitatif dengan pendekatan deskriptif kuantitatif. Teknik analisis data yang digunakan yakni analisis regresi linear sederhana. Adapun teknik pengumpulan data yang digunakan dalam penelitian ini ialah angket, lembar observasi dan dokumentasi. Sedangkan teknik analisi data yang digunakan: 1) uji normalitas menggunakan Kolmogrov Smirnov dengan bantuan SPSS versi 15.0 for window; 2) uji validitas yang dipakai adalah validtass internal; 3) uji reliabilitas menggunakan Alpha Cronbach dengan menggunakan SPSS 15.0 for windows; 4) uji hipotesis menggunakan uji Regresi Sederhana.

\section{HASIL DAN PEMBAHASAN}

Hasil penelitian mengenai pengaruh pendekatan saintifik terhadap motivasi belajar siswa kelas IV SD YPK 4 PNIEL Kota Sorong, dapat dijabarkan dalam 2 tahap, yaitu uji asumsi klasik dan uji hipotesis sebagai berikut :

Uji validitas yang menggunakan teknik Expert Judgement, telah dilakukan dengan didiskusikan kepada Dosen selaku tim validasi kuisioner pada Universitas Pendidikan Muhammadiyah Sorong, yakni Bapak Fuad Ardiansyah, M.Si.

Sebelum dilakukan uji hipotesis maka terlebih dahulu dilakukan uji reliabilitas. Uji reliabilitas digunakan untuk menguji kehandalan seluruh pernyataan penelitian yang tercantum pada kuisioner. Dengan total 20 butir pernyataan, yang terdiri dari 10 butir pernyataan untuk variabel Pendekatan Saintifik, dan 10 butir pernyataan untuk variabel Motivasi Belajar. Hasil uji data selanjutnya akan dibandingkan dengan nilai minimum Cronbach's Alpha yaitu 0,60. Berdasarkan hasil uji reliabilitas menggunakan SPSS 15.0 for windows, maka dapat dijabarkan outputnya pada tabel 1 dan 2 dibawah ini :

Tabel 1. Output uji reliabilitas pendekatan saintifik dan motivasi belajar

\section{Reliability Statistics}

Cronbach's Alpha N of Items .832 10

Tabel 2. Hasil uji reliabilitas motivasi belajar

\section{Reliability Statistics}

Cronbach's Alpha N of Items .847 10

Sumber : Data primer diolah, 2019 
Pengujian normalitas dilakukan menggunakan uji Kolmogorov Smirnov-Z, dengan hasil uji pada tabel 3 sebagai berikut : Tabel 3. Uji normalitas Kolmogorov smirnov

\begin{tabular}{llr} 
& \multicolumn{2}{c}{ Unstandardized Residual } \\
\hline $\mathrm{N}$ & & 30 \\
Normal & Mean & .0000000 \\
Parameters $^{\mathrm{a}}$ & Std. Deviation & 1.23786453 \\
Most Extreme & Absolute & .131 \\
Differences & Positive & .069 \\
& Negative & -.131 \\
& Kolmogorov-Smirnov Z & .715 \\
Asymp. Sig. (2-tailed) & .686 \\
\hline
\end{tabular}

a. Test distribution is Normal.

Sumber : Data primer diolah, 2019

Diketahui bahwa Nilai signifikansi yang ditujukan pada Asymp.Sig (2-tailed) adalah sebesar 0,686. Dengan demikian, berdasarkan syarat uji normalitas yang dikemukakan oleh Nanang (2010), bahwa jika nilai sig >0,05, maka data berdistribusi normal. Sehingga mengacu pada tabel diatas, diketahui bahwa sig $=0,686>0,05$, maka data penelitian terbukti berdistribusi normal.

Pengujian selanjutnya dilakukan uji hipotesis. Uji hipotesis dalam penelitian ini menggunakan uji regresi linear sederhana. Berdasarkan hasil olah data pada SPSS, diketahui bahwa :

Tabel 4. Uji regresi Linier sederhana

\begin{tabular}{|c|c|c|c|c|c|}
\hline & Unstandardized & Coefficients & $\begin{array}{l}\text { Standardized } \\
\text { Coefficients }\end{array}$ & & \\
\hline Model & $B$ & Std. Error & Beta & $t$ & Sig. \\
\hline 1 (Constant) & 8.163 & 1.856 & & 4.398 & .000 \\
\hline $\begin{array}{l}\text { Pendekatan Sainififik } \\
\text { a. Dependent Variable: }\end{array}$ & $\begin{array}{r}.488 \\
\text { ativasi Belaiar }\end{array}$ & .135 & .531 & 3.314 & .003 \\
\hline
\end{tabular}

Sumber : Data primer diolah, 2019

Perbandingan nilai sig dilakukan dengan mengacu pada nilai probabilitas sig adalah 0,05 . Berdasarkan pada tabel diatas, maka dapat dilihat bahwasanya nilai signifikansi (Sig) adalah sebesar 0,03. Dimana 0,03 $<0,05$, maka dapat disimpulkan $\mathrm{H}_{0}$ ditolak dan $\mathrm{H}_{1}$ diterima. Bahwasanya pengaruh antara metode pembelajaran menggunakan pendekatan saintifik berpengaruh secara signifikan terhadap motivasi belajar siswa.

Menurut pendapat yang dikemukakan oleh Ghazali (2013), bahwa suatu variabel dapat dikatakan berpengaruh terhadap variabel lainnya jika terbukti $t_{\text {hitung }}>t_{\text {tabel. }}$. Berdasarkan pada tabel 4 diatas, maka dapat dilihat bahwasanya $t_{\text {hitung }}$ adalah sebesar 3,314. Dan $t_{\text {tabel }}$ pada df $n-k=28$, pada taraf 0,025 , maka didapatkan $t_{\text {tabel }}=2,048$.

Maka $t_{\text {hitung }}>\mathrm{t}_{\text {tabel }}, 3,314>2,048$, maka dapat ditarik kesimpulan bahwasanya $\mathrm{H}_{0}$ ditolak dan $\mathrm{H}_{1}$ diterima. Artinya pembelajaran dengan pendekatan saintifik memiliki pengaruh yang signifikan terhadap motivasi belajar.

Pada penilitian sebelumnya yang dilakukan oleh Dewi Anjani (2018), menunjukan bahwa pendekatan saitifik memberikan hasil yang lebih baik. Dibuktikan nilai sig variabel motivasi belajar $=0.000<0,05$, sehingga hasil diterima, yang berarti pendekatan saintifik yang diterapkan berpengaruh motivasi belajar siswa pada SD Muhammadiyah 16 Karangasem.

Selanjutnya, kembali didukung pada penelitian yang dilakukan oleh Sri Haryati (2011) bertujuan untuk mendeskripsikan peningkatan aktifitas peserta didik. Dengan hasil penelitian menunjukan perencanaan pembelajaran tematik terpadu dengan pendekatan saintifik meningkatkan aktifitas fisik peserta didik mengalami peningkatan. Sehingga dapat disimpulkan bahwa dengan pendekatan saintifik dalam pembelajaran dikelas 1 maka motivasi dapat ditumbuhkan lebih baik sehingga pembelajaran menjadi aktif lebih menyenangkan bagi siswa. 
Dimana perencanaan pembelajaran tematik terpadu dengan pendekatan saintifik untuk meningkatkan aktivitas fisik peserta didik di kelas I SDN 05 Delta Pawan, mengalami peningkatan sebesar 1,37 kategori kurang; 2) Pelaksanaan pembelajaran meningkat sebesar 1,45 kategori kurang; 3) Aktivitas fisik peserta didik mengalami peningkatan sebesar 29,26 $\%$ kategori rendah; 4) Aktivitas mental peserta didik mengalami peningkatan sebesar 46,34 \% kategori cukup; 5) Aktivitas emosional peserta didik mengalami peningkatan sebesar 33,33\% kategori rendah. Dengan hasil keseluruhan bahwa pendekatan saintifik dalam pembelajaran di kelas I , berdampak positif dan bermakna bagi peserta didik.

Tabel 5. Koefisien nilai t

\begin{tabular}{lrrrr}
\hline Model & R & RSquare & $\begin{array}{c}\text { Adjusted R } \\
\text { Square }\end{array}$ & $\begin{array}{l}\text { Std. Error of } \\
\text { the Estimate }\end{array}$ \\
\hline 1 & $.531 \mathrm{a}$ & .282 & .256 & 1.25978 \\
\hline
\end{tabular}

Sumber : Data primer diolah, 2019

Diketahui bahwa nilai koefisien adalah 0,531. Nilai ini dapat diinterpretasikan bahwa hubungan kedua variabel penelitian berada pada kategori "Cukup Kuat" (Sugiyono, 2006). Artinya, metode pembelajaran dengan pendekatan Saintifik memiliki pengaruh yang cukup kuat dalam meningkatkan motivasi belajar siswa.

Melalui tabel 5 juga diperoleh nilai $\mathrm{R}$ Square, atau koefisien determinasi (KD) yang menunjukkan seberapa bagus model regresi yang dibentuk oleh interaksi variabel bebas dan variabel terikat. Nilai KD yang diperoleh adalah sebesar $(0,282 \times 100)=$ $28,2 \%$, yang dapat ditafsirkan bahwa variabel bebas (Pendekatan Saintifik) memiliki pengaruh kontribusi sebesar 28,2\% terhadap variabel Y (Motivasi Belajar), sedangkan sisanya yakni $71,8 \%$ lainnya dipengaruhi oleh faktor-faktor lain diluar dari variabel Motivasi Belajar.

\section{KESIMPULAN}

Terdapat pengaruh antara pendekatan saintifik terhadap motivasi belajar, dilihat dari $t_{\text {hitung }}>t_{\text {tabel }}$, yakni 3,314>2,048, dan berdasarkan nilai sig yakni $0,03<0,05$, maka dapat ditarik kesimpulan bahwa $\mathrm{H}_{0}$ ditolak dan $\mathrm{H}_{\mathrm{a}}$ diterima. Artinya pembelajaran dengan pendekatan saintifik memiliki pengaruh yang signifikan terhadap motivasi belajar. Adapun kualitas pengaruh yang diberikan adalah sebesar $28,2 \%$, sedangkan $71,2 \%$ disebabkan oleh faktor lain diluar dari motivasi belajar

\section{DAFTAR RUJUKAN}

Asrul, A., Ridlo, S., \& Susilo, S. (2018). Creative Thinking Analysis, Motivation and Concept Mastery on Learning of Cooperative Discovery Model in Elementary School. Journal of Primary Education, 7(1), 48-56.

Ghozali, Imam. (2013). Aplikasi Analisis Multivariate dengan Program IBM SPSS 21 Update PLS Regresi. Badan Penerbit Universitas Diponegoro : Semarang

Hamalik. (2011). Proses Belajar Mengajar. Bumi Aksara: Bandung.

Kemendikbud. (2013). Pendekatan, Jenis Dan Metode Penelitian Pendidikan. T.P: Jakarta.

Lawson, Anton, et al. (2000). Development of Scientific Reasoning in College Biology: Do Two Levels of General Hypothesis-Testing Skills Exist? 37(1). 81-101. National Science Foundation.

Lawson, E.T., Gordon, C., Mensah, A., \&Atipoe, e. (2015). Developing Tools for Community-Based Environmental Education for Migrant Children adn Youth in Ghana. Journal of Education and Learning, (online), Vol.4, No. 2. 
Lestari, W., Pratama, L. D., \& Jailani, J. (2018). Implementasi Pendekatan Saintifik Setting Kooperatif Tipe STAD Terhadap Motivasi Belajar Dan Prestasi Belajar Matematika. AKSIOMA. Jurnal Matematika dan Pendidikan Matematika, 9 (1), 29-36.

Martono, Nanang. (2010). Metode Penelitian Kuantitatif. Raya Grafindo Persada : Jakart.

Neeman, Y.P., \& Barak, M. (2013). Exploring Students' Perceptions about Learning in School: An Activity Theory Based Study. Journal of Education and Learning, (online), Vol.2, No. 3.

Puspitasari, Dewi A.W. (2018). Pengaruh Pendekatan Saintifik Terhadap Motivasi Belajar Siswa Kelas IV di SD Muhammadiyah 16 Karangasem. Skripsi. Universitas Muhammadiyah Surakarta
Sadriani, S., Rede, A., \& Darmadi, I. W. (2018). Pengaruh Pendekatan Saintifik Terhadap Motivasi Belajar Sains Pada Siswa Kelas IV SD Inpres 1 Sidondo. Jurnal Kreatif Online, 6(3).

Sani, R. A. (2014). Pembelajaran saintifik untuk implementasi kurikulum 2013.

Sardiman, A.M. (2010). Interaksi dan Motivasi Belajar Mengajar. Rajawali Pers: Jakarta.

Sugiyono. (2006). Metode Penelitian Kuantitatif, Kualitatif dan $R$ \&. D. Alfabeta : Bandung.

Sumayasa, I. N., Marhaeni, M. P. A. N., \& Dantes, N. (2015). Pengaruh Implementasi Pendekatan Saintifik Terhadap Motivasi Belajar dan Hasil Belajar Bahasa Indonesia pada Siswa Kelas VI di Sekolah Dasar Se Gugus VI Kecamatan Abang, Karangasem (Doctoral dissertation, Ganesha University of Education). 